\title{
Sciendo
}

\section{Legal Engineering of the Anti-Abuse Rule in ATAD: Architecture of the Regression Tree Model}

\author{
Kaido Künnapas \\ TalTech Law School \\ Tallinn University of Technology \\ Ehitajate tee 5, \\ Tallinn 19086, Estonia \\ Email: kaido.kunnapas@taltech.ee
}

\begin{abstract}
Every taxable arrangement is subject to an anti-abuse test. Abusive arrangements are treated as not valid for tax purposes, which is similar to the treatment of artificial arrangements in civil law. The European Union has introduced in its Anti-Tax Avoidance Directive a general anti-abuse test which must be transposed into the domestic laws of Member States. Such a test has its inner structure, consisting of an elimination and requalification stage, while the elimination stage entails genuineness and a tax benefit test. The general anti-abuse test has a great potential (or scalability when speaking in the language of start-ups) of being automated and integrated into different legal application processes (such as taxpayer self-assessment systems, transactions certified by public notary or merger and acquisition deals) to discover debt push down abuses or other arrangement structures which may have abusive content. While the best method for create a reliable algorithm is a decision tree type model, the inner ambiguity of the general anti-abuse test prevents using the full benefits of automation of tax laws. The purpose of this article is to design a decision tree type model for the test and address the main challenges of such a model, both from the perspective of the clarity of concepts and the quality of input information such an engine would use.
\end{abstract}

Keywords: anti-abuse rule, ATAD, decision tree, legal algorithms, legal engineering, machine learning, regression tree 


\section{Introduction and the problem}

International tax law aims for tax justice through distributing taxation rights between states and harmonizing rules designed to prevent abuse of the law. It has been long understood by the member states of the Organization for Economic Co-operation and Development (OECD) that it is beneficial to clarify, standardize, and confirm the fiscal status of taxpayers engaged in various activities to provide common solutions to similar taxable situations (OECD, 2019, p. 9). However, the layers of anti-abuse rules and substance-over-form principle seem to be a hindrance in the effort to achieve uniform application of tax laws. As aptly noted by Kuzniacki, "The numerous new anti-avoidance rules resulting from OECD/G20 BEPS initiative and its derivatives [...] increase the complexity of laws, thereby further exacerbating the difficulties experienced with tax compliance and tax supervision" (Kuzniacki, 2018). It is true that ambiguity is somewhat inherent in anti-abuse rules in tax law, as it has been recognized even by the European Court of Human Rights in Yukos v. Russia ([2011], para. 393) case. This does not mean that such rules should become so ambiguous that the constitutionality becomes questionable.

At the European Union (EU) level, the above criticism can be extended to the general anti-abuse rule (GAAR), introduced in the Council Directive (EU) no. 2016/1164 of 12 July 2016 on laying down rules against tax avoidance practices that directly affect the functioning of the internal market (ATAD). The GAAR is a test addressed in ATAD Article 6(1), stating that non-genuine arrangements are set aside from taxation, provided that the main purpose or at least one of the main purposes of designing the arrangement as it was done was to have a tax benefit. The minimum level of this test is harmonized in all Member States, while the Member States may also introduce stricter rules catching a wider spectrum of arrangements (ATAD, Recital 3, Art. 3). The ambiguity in the wording and the new concepts it introduced has been highlighted by many authors, while they also generally recognize the need for such a regulation (see de Wilde, 2018; Zimmer, 2019; Kuzniacki, 2021). While the test consists of a requalification/elimination stage, it is unclear to what extent it limits Member States' freedom to decide what to tax and what not to tax (Künnapas, 2020, p. 99). As it impedes the principle of legal clarity, demand for a simple application mechanism becomes more relevant than ever.

Automated decision-making systems in law can counteract to such negative effects. The EU supports and recognizes the use of AI in public administration, 
provided that those systems do not entail high risk to legal and natural persons (Proposal for Artificial Intelligence Act, Preamble, p. 37). As per Longarte (2020), a distinguished expert in digital economy taxation, tax law is especially suitable for involving AI in policy design. Indeed, in an ideal world, the OECD Model Tax Convention (MTC) would not be just a document, supported by its commentaries-it would also include an official tool for allocating taxation rights based on data inserted into the system and logic-based algorithms developed by the OECD. More than 3,000 bilateral tax treaties could be supported by such a tool and integration with crossborder arrangements (such as salary paid for cross-border employment) would be supported. However, coming back to the state of tax and legal tech as of today, there are obviously problems with understandability and explainability of output when complex AI technologies become involved (Yale Law School, Information Society Project \& Immuta, 2017, p. 4).

Logic-based decision automation technologies can find practical application in tax laws, especially in the era where making deals and concluding agreements becomes integrated into the hardware more than ever. The author keeps in mind the so-called expert systems which use formal logic and coded rules to engage reasoning based on closed-rule algorithms, falling under the AI umbrella (Raso et al., 2018, p. 10). A similar method-question-answer engines, i.e., a supervised classifier system and information retrievalwas described by Blazej Kuzniacki in the context of building a predictive algorithm for automating the principal purpose test, or PPT (Kuzniacki, 2018, p. 9). PPT is a tool for eliminating abusive arrangements under the OECD MTC and Multilateral Instrument (MLI), therefore having functions similar to the GAAR. The purpose of automation of such an international concept was to achieve a uniform application of it.

The author finds that designing automated application logic of the ATADbased GAAR may have practical value in application of law. Besides enhancing legal certainty and access to law through compliance self-check applications available for taxpayers, it would contribute to a more coherent application of the minimum standard in ATAD and the development of tax law in that respect. Another positive side effect of automation and development of logicbased decision-making systems may be that the legislature would put more emphasis on designing the architectural logic of legal norms.

As the author is not aware of any specific research on this topic besides Kuzniacki's approach to the PPT, the purpose of this article is to create a closed-rule decision tree type algorithm on the GAAR and address the most 
significant issues faced upon feeding data to such a decision-making process. The author seeks to answer the following questions: what is the design of the closed-rule decision tree type algorithm on the GAAR and what are the main challenges related to input information to such a decision-making process. As it is a rather novel topic with a practical focus, this article addresses the issues at a high level and maps the connection points between the GAAR law and the decision tree type algorithm design.

Being a qualitative analysis, a literature review was compiled to develop an understanding of the above topics and to answer the research question. For the purpose of the latter, the author analysed the general framework of a decision tree model used in machine learning and identified the interlink between the elements of the model and the GAAR. The focus of this article is on combining the structure of the GAAR and the decision tree model (i.e., the syllogism of applying the GAAR test) and not so much on the data mining aspects of sourcing and interpreting the information which is fed into such a syllogism. As the GAAR applies to corporate income taxes only (ATAD, Art. $6(1)$ ), the scope of this research is limited to corporate income taxes.

\section{The fundamentals of the decision tree model in machine learning $-a$ basis for designing practical applications}

Automation of anti-abuse rules may provide extra value when integrated into digital drafting, information sourcing or decision-making processes. Since at the centre of it would be a decision-making engine, it would require input data to make the engine work. While at the initial stages the engine should run manually, using machine-learning techniques enables it to operate independently over time.

An example of that could be a GAAR engine which is connected to the automated contract drafting engines as are used by public notaries in Estonia. While sourcing input information on the legal form (from agreement), economic content (from asset transfer information), intentions of the parties (statements of intent checked by notaries) and reflection of such intentions in economic reality (double checking of such statements of intent against publicly available information from databases, for example), the engine can make a decision on potential anti-abuse risk by processing this information. Over time, the engine can learn patterns and make more 
reliable risk assessments. To design such an engine, the decision tree model well-known in machine learning could be used.

A GAAR engine could be a useful tool when connected to smart contracting. As per Solarte-Vásquez and Nyman-Metcalf, "smart contracting holds genuine interest about the effects and affordances of novel technologies in contracts that could promote real transformations in the traditional governance of businesses and the markets" (Solarte- Vásquez \& NymanMetcalf, 2017, p. 217). While Solarte-Vásquez and Nyman-Metcalf argue that smart contracting governance capacities could become beneficial in the areas of risk management, transaction design for proper communication, association and engagement rather than control, and intra-firm information management and coordination across strategic levels via self-regulatory documents (Solarte-Vásquez \& Nyman-Metcalf, 2017, p. 219), the author finds that it can become beneficial also in tax compliance area when being tied with anti-abuse testing. If placed into the contracting cycle as described by Jaakkola, which has been one of the theoretical foundations for SolarteVásquez and Nyman-Metcalf (2017, p. 219), it would be integrated into the stage of 'Interface of the contracting outcome, agreement or relational text' or 'Compliance processes and operations or renegotiation'.

Machine learning is a subcategory of AI, marking systems which improve their performance through learning from data patterns. The most widely used machine-learning methods are supervised learning methods (Jordan \& Mitchell, 2015, p. 257). Supervised learning methods are machine-learning techniques that involve inferring a function or learning a classifier from the training data in order to perform predictions on unseen data (Allahyari et al., 2017). There is a broad range of supervised methods such as nearest neighbour classifiers and decision trees. Supervised learning methods can be based on probabilistic classifiers or rule-based classifiers. (Allahyari et al., 2017)

In supervised symbolic machine learning, the result of the learning process is represented as symbols, either in the form of logical statements or as graph structures (Helsgaun, 2019). As opposed to non-symbolic machinelearning techniques, which in many cases are not able to provide results that are accurate (operating based on probability) or reasoned (the so-called "black boxes" in reasoning processes), supervised symbolic machine-learning can provide exact, logic-based answers within the framework of the logic structure used. The number of ethical problems encountered by this method is also much smaller, as the results are more easily explainable (Mittelstadt 
et al., 2016, pp. 1-21). This makes logic-based machine-learning methods more usable in the legal and tax sectors as the explanations supporting the outcomes have significant importance in those fields. While automated decision-making may decrease the transparency of evaluation processes depending on the designer's choices, a rule-based system can explain precisely how every variable was set and why each conclusion was reached (Zalnieriute, Moses \& Williams, 2019, pp. 437, 440).

A decision tree is one of the supervised machine-learning algorithms in which the answer to the question is reached by going through a hierarchical decision process. Allahyari and others note, "[a] decision tree is [...] a hierarchical tree of the training instances, in which a condition on the attribute value is used to divide the data hierarchically" (Allahyari et al., 2017). According to de Jong and Derksen,

[a] decision tree partitions the training data set into smaller subdivisions based on a set of tests defined at each node or branch. This may be compared to the analysis of legislation, which is also often hierarchically structured (e.g., only if sub article 1 applies, then one may proceed to sub article 2). [...] Inclusion of decision tree analysis will diminish the risks of a black box occurrence, as long as the decision tree is able to provide a clear overview of its structure. (de Jong \& Derksen, 2019, p. 15)

Furthermore,

[i]n order to do so, the meaning of certain text fragments needs to be identified by labelling them-which is an extensive manual taskand secondly, an algorithm needs to be deployed to recognize similar meanings in references and relating subjects. Finally, an algorithm needs to combine and/or structure the hierarchy of related meanings. (de Jong \& Derksen, 2019, p. 15)

In very simplistic form, decision trees follow the construction of 'if ... then.... else...', which is familiar to lawyers as being the syllogism in regulative legal norms. Indeed, in legal theory, the structure of a legal norm includes also the element of enforcement and is seen rather in the format of (x) fact > element of enforcement (x) legal outcome (Aarnio, 1996, p. 58).

However, it most probably takes some time until AI-based tax systems become so advanced that we are willing to build automated enforcement into these. So to look into possibilities to apply it to the GAAR, the author first needs to analyse the inner logic of the GAAR which should be used as 
a basis for developing further algorithms. It comes down to identifying the concepts used in the GAAR and creating a hierarchy of those concepts. The author looks into this task in the following sections.

\section{Interlink between the decision tree model and the GAAR}

\subsection{Syllogisms in international tax law on direct taxes and the GAAR}

Taxation has been seen as one of the most open areas for automation as per Frey and Osbourne (2017, pp. 254-280). Ignacio Longarte (2020) highlights the reasons for that as its "strong numeric and categorization base". In other words, automation of tax law is supported by the firm syllogisms it follows. The concept of a syllogism is similar to the concept of an algorithm. An algorithm is "a finite, abstract, effective, compound control structure, imperatively given, accomplishing a given purpose under given provisions" (Hill, 2016, p. 47). A legal syllogism functions also as a control structure, enabling it to test whether the real life facts correspond to the abstract preconditions in the 'if ... then....else...' statement.

International tax law in general seems to be an ideal process to be managed by logic-based machine-learning methods-such as decision trees-in which the model relies on the hierarchies embedded in relevant legal norms and concepts. Kuzniacki has proposed a logic-based supervised learning classifier system combined with semi-supervised pattern recognition for a principal PPT introduced in the Multi-Lateral Instrument supplementing the OECD Model Convention on direct taxes (Kuzniacki, 2018). International tax law mostly addresses the division of taxation rights between the states, resolving conflicts of national tax law. Such conflicts usually emerge from overlaps of tax jurisdiction but can also arise from gaps between them, as we have seen from recent hybrid mismatch rules introduced in ATAD2 (Council Directive (EU) 2017/952 of 29 May 2017 amending Directive (EU) 2016/1164 as regards hybrid mismatches with third countries). The inherent syllogism — to be understood as deductive methods of reasoning - in international tax law therefore provides binary outcomes. The OECD MTC has traditionally followed the "classification and assignment of sources" principle, which attaches full or limited source taxation to certain classes of income and capital and assigns the right to tax other types of income and capital exclusively to the state of residence (OECD, 2014, p. 37). As the purpose of the MTC is to distribute taxation rights between 
the source and residency state, the outcome of the syllogism is usually either "taxation at the source state" or "taxation at the residency state". For some types of passive income, the taxation rights are divided between the parties to the MTC based double tax treaty, see specifically Articles 10 (Dividends), 11 (Interests) and 12 (Royalties). The same distributive binary method can be found in the EU direct tax law, in which the right to tax dividends, interest, and royalties is divided between two Member States.

Developed from the primary and secondary EU law, the anti-abuse rule harmonizes the minimum level of protection for national corporate tax systems against tax avoidance practices across the EU (de Wilde, 2018, s. 14.1.; ATAD, Recital 11 \& Art. 3). It requires setting aside, for tax purposes, non-genuine arrangements which have been put into place for the main purpose, or one of the main purposes, of obtaining an unintended tax advantage. The GAAR functions differently from the above "classification and assignment of sources" rule. It aims to eliminate the misuse of tax laws. However, the outcome of applying its test would again be binary, qualifying the arrangement as "to be set aside from taxation" or "not to be set aside from taxation". The internal structure of Article 6 of the ATAD divides the anti-abuse rule into two distinct stages-elimination and requalification. According to Article 6 of the ATAD, the elimination stage of the anti-abuse rule is as follows:

1. For the purposes of calculating the corporate tax liability, a Member State shall ignore an arrangement or a series of arrangements which, having been put into place for the main purpose or one of the main purposes of obtaining a tax advantage that defeats the object or purpose of the applicable tax law, are not genuine having regard to all relevant facts and circumstances. An arrangement may comprise more than one step or part.

2. For the purposes of paragraph 1, an arrangement or a series thereof shall be regarded as non-genuine to the extent that they are not put into place for valid commercial reasons which reflect economic reality.

The arrangements (or, to be precise, the misconception of having a legally valid, for tax purposes, arrangement) subject to elimination from taxation are requalified as per Article 6(3) of the ATAD as follows:

3. Where arrangements or a series thereof are ignored in accordance with paragraph 1 , the tax liability shall be calculated in accordance with national law. 
The grammatical interpretation of Article 6 of ATAD shows that the elimination stage of the GAAR consists of the following concepts or variables: arrangement (or series of arrangements), genuineness of the arrangement, tax advantage, the object or purpose of the law reflecting the tax advantage, and the purpose of obtaining the tax advantage. Within the boundaries of the grammatical interpretation of Article 6, the concept of genuineness can be split into sub-categories of "valid commercial reasons" and "reflection in the economic reality". Those two categories combined have the same information value as the concept of genuineness. The syllogism above can be shown as a regressive decision-making process as follows:

Figure 1. A basic decision tree model for the elimination stage

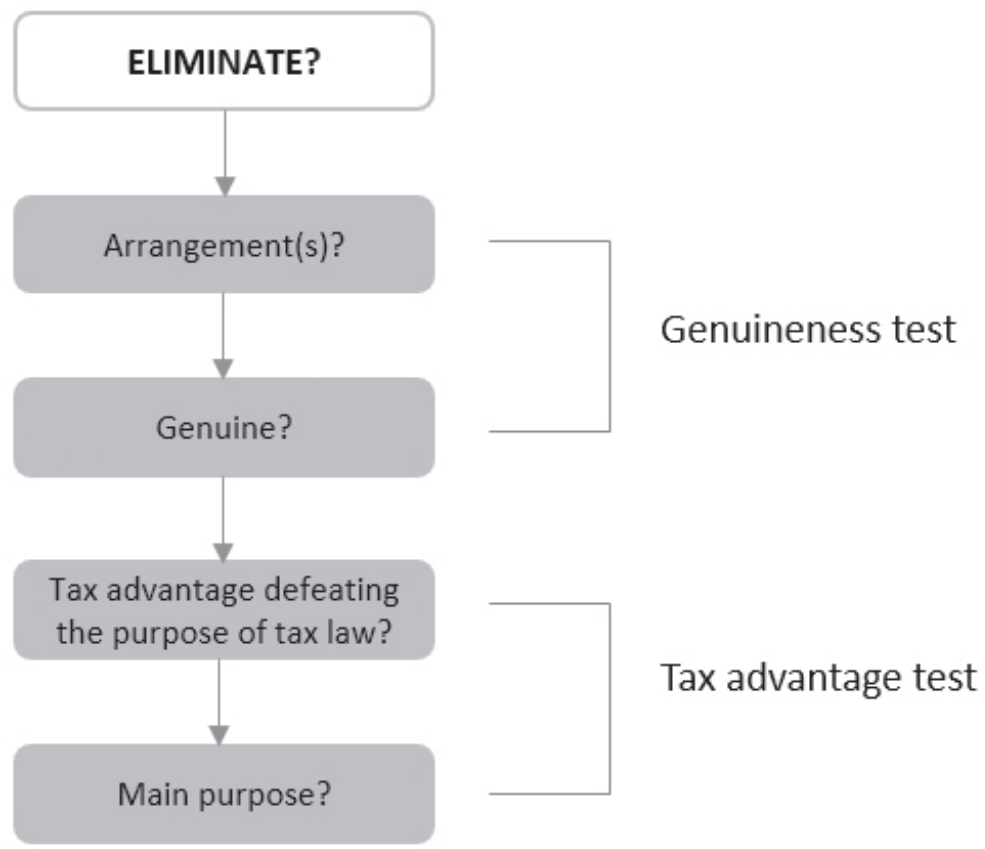

\subsection{A decision tree model for the GAAR}

The hierarchy of the concepts in a legal norm determines which concept should be the top one in the decision tree (i.e., a root node).

The hierarchy of the concepts above makes it clear that the syllogism for confirming or rejecting the abusive treatment of tax laws should start with the question of whether there is an arrangement. If there is no arrangement, 
Figure 2. A detailed decision tree model for the elimination stage. The left pillar focuses on analysing single arrangement and the right side focuses on analysing the set of arrangements, i.e., the big picture

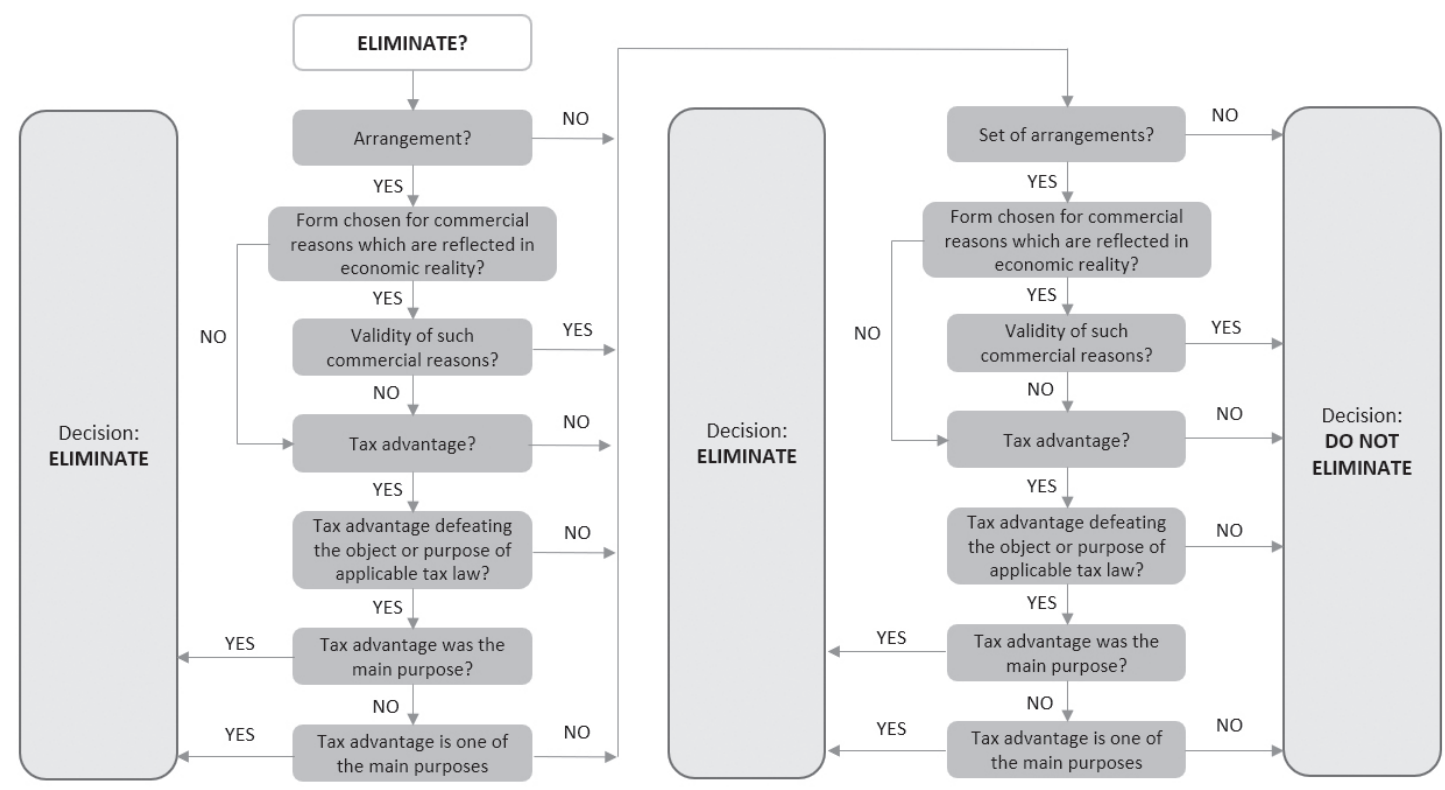

the test cannot be triggered. This can be justified by four statements. First, there is no taxable event of which its genuineness could be assessed. Genuineness is a characteristic of an arrangement which cannot exist independently of the arrangement. Second, there is no tax treatment of the arrangement to be compared against an alternative tax treatment in the context of the tax advantage test. Third, the question of defeating the object and purpose of tax law can be assessed only in the context of the tax advantage test. Finally, the existence of a main purpose of an arrangement is assessed in the context of the tax advantage test, which requires prior identification of an arrangement. The assessment and decisions on other concepts can be made after the arrangement is identified.

As genuineness is the closest term to the arrangement, being a characteristic of it, the second logical question to be addressed in the model is whether the arrangement is genuine. Doing that, the part of the objective elimination test focusing on the genuineness of arrangement is accomplished.

Following with the subjective tax advantage test, the first question to be logically addressed is whether there is a tax advantage involved or not. 
To answer this question, comparable arrangements or situations must be identified and tax treatments of such arrangements or situations must be compared. When a tax advantage is identified, it must be determined whether or not such tax advantage defeats the object or purpose of the applicable tax law. This is done by teleological interpretation by which the intent (telos) of the legislator to provide such a tax advantage is identified. If the purpose of the applicable tax law was not to provide the tax benefit that the party to the arrangement gained, the last part of the test executes, addressing the question of whether having such a tax advantage was the main purpose or one of the main purposes of creating the non-genuine arrangement. The syllogism above can be shown as a regressive scheme as visualized in Figure 2.

\section{The main concerns in designing the GAAR engine}

\subsection{Source of concerns}

The decision tree model above reflects the inner structure of the norm and relies on the grammatical interpretation of it. As the process of application of law has in principle three levels-identifying the conditions which should be met and the inner hierarchy of such conditions for triggering the norm, identifying what legal facts are present and making a decision on application or non-application of the norm (Narits, 2004, p. 10)-and the purpose of legal engineering is to automate the third step, issues may arise from the first two steps.

The author has outlined a list of issues which are encountered upon interpreting the law and identifying legal facts and which would require the most attention. The purpose of this article is not to resolve such issues as each of those would require extensive analysis of law and jurisprudence. Instead, it aims to highlight the issues in order to prevent built-in and unnoticed bias in anti-abuse decision tree model on the GAAR.

\subsection{Issues with interpreting the law}

It is argued that algorithms are inevitably value-laden (Mittelstadt et al., 2016, p. 1). This applies to both sourcing the input information and generating the output information. In terms of machine-learning models, one of the sources of bias comes from the ambiguity of the legal content of anti-abuse rules. The more ambiguity in the legal norm, the more designer bias it enables. Such bias is amplified by the fact that there are a number of 
approaches to anti-abuse methods and their level of invasiveness can vary a lot. For example, the Blue J Legal application, developed for the economic substance test in US tax law, was proposed by the developers. This test involves a five-factor analysis that informs the origin, structure, economic impacts, and non-profit effects of the transaction, as well as taxpayers' risk level (Yan, 2019). Tests applied outside of the US may have totally different approaches to identifying abusive operations.

In the context of the GAAR, the starting point of analysis is an arrangement. The scope of the arrangement determines which type of input information the algorithm requires to go through the decision process and from which sources such information could be acquired. It sets the scene.

Although being the trigger for the GAAR test, the concept of 'arrangement' is not defined in the Directive. Therefore, first the legal definition of arrangement should be identified, having in principle two ways to approach. First, it can be seen as an objective legal qualification of a real-life set of facts. For example, one may assess whether the sale of a shareholder's personal assets through a company (i.e., capitalization of a company, following the sale of such asset by the company to "change" the form of a capital from asset to cash) should be requalified to a direct sale agreement between a shareholder and a third party buyer. If requalified, it would lead to a conclusion that the capitalization and sales agreement between the company and the third party buyer are seen as abusive acts (Maret Lilleorg v. Tax Board [2012]; Marge Sirge v. Tax Board [2011]). To trigger the test of whether or not this is an arrangement, the concepts of 'capitalization of company', 'asset transfer' and 'money transfer' constituting an arrangement should be identified among other relevant aspects (Künnapas, 2020, pp. 112-113). The intentions of the taxpayer are irrelevant at this point, as arrangements are objective by their nature. Such an approach is taken, for example, by Estonian Supreme Court in its case-law on applying the substance over form principle, in which the economic content is seen as transfer of assets or cash (Kõrgessaar v. Tax Board [2001]). Determining the objective scope of the arrangement first requires an independent data sourcing and a respective decision on sources by some agent, creating the first point of risk for bias and prejudice in these decisions. The second approach could be that an arrangement can be a subjective legal qualification of a certain set of facts which the party to the arrangement demonstrates to be existing, which means that the existence of an arrangement is determined based on the content the party to the arrangement wants to show. Such an approach requires sourcing 
input information about the subjective understanding of the transaction party.

The structure of the GAAR determines that the arrangement should be understood as a notion with objective nature because the reasons (either commercial or tax-related) are assessed at the later stages. Making a decision on existence of arrangement requires identifying change in the rights and/or obligations of a person which in one of its possible variations may be, in principle, taxable with corporate income tax. When coming back to the example of a sale of shares through the company, the arrangements would include transfer of the ownership to the asset from private person to its company, acquisition of share in the company, transfer of asset by the company to a third person and receipt of purchase price by the company. Provided the asset is registered in a relevant public database reflecting the ownership to the asset and the shares in the company are registered in the public register, it would be relatively easy for the system to obtain necessary information through data sourcing.

However, the difficulty arises in analysing the right pillar in Figure 2, i.e., whether the set of arrangements may be abusive in nature. It is unclear how to determine what arrangements should be taken into account when assessing the big picture and what are the time limits and person-based limits to it.

The above difficulty also relates to the issue of determining tax advantage. Obtaining a tax advantage is a must-be condition for elimination. Tax advantage can be obtained by paying less tax or doing it on more beneficial terms, e.g., having a tax deferral. It is not possible to assess tax advantage without first identifying all the possible alternatives to the arrangement as seen by the taxpayer and identifying at least one of those which would provide a tax advantage under the same objective economic content, but in a different form (e.g., with a reduced number of steps). Identifying tax advantage would require the system to have access to the description of all other types of arrangements which would correspond to the economic content of arrangement as identified in the first step. Such an overwhelming task can be, however, avoided by first identifying whether having the tax advantage has been the main or one of the main considerations for the taxpayer to choose the form. Identifying the purpose obviously requires collecting data on the taxpayer's subjective motives, which should also determine which arrangement was the genuine one, disguised by the artificial one. However, comparing such a subjective understanding as presented by the taxpayer 
against all alternative structures is the challenging part of this test. This requires the system to identify the economic content of the arrangement and find all tax-relevant legal concepts which would represent alternative arrangement structures.

\subsection{Issues with identifying legal facts}

The GAAR test requires identifying a variety of facts either of objective or subjective nature. While objective facts demonstrate the state of matters, it is not so difficult to find reliable sources for input information. However, subjective facts that demonstrate the intent and mind of a taxpayer entail much more ambiguity and risk of bias for choosing the source for input data. Administrative officials and judges face the same issue when assessing which evidence reflecting the taxpayer's intentions and considerations are trustworthy and which are not. To map such points in the GAAR decision tree model in Figure 3 below, the following symbols are used: the objective criteria is marked with $O$, subjective criteria are marked with $S$ and decision on the validity of certain facts is marked with $D$.

The elimination test includes several subjective categories which must be identified based on information from objective sources. As summarized by Piantavigna in his extensive analysis on the role of subjective element, "it would involve an enquiry into the willingness of tax payer to enter into arrangement and subjective consequences sought" (Piantavigna, 2018, p. 230). Furthermore, "[t]he subjective element should be the rationale underlying the chosen transaction/arrangement, in contrast with the model behaviour suggested by the revenue authorities" (Piantavigna, 2018, p. 230 ). The overall reasoning of this criteria is that the taxpayer should have non-tax reasons for choosing the legal form that it chose and such reasons should align with actual facts of the business and overall principles and rules followed in economic life. Piantavigna (2018, p. 230) also concludes that current international instruments do not have a uniform approach to subjective elements and legal uncertainty therefore easily emerges. Thus, with the subjective elements we face a mix of difficulties arising from the ambiguity in the content of rule and also the reliability of input information and choosing the sources for information which is deemed to be reliable. Before automating the GAAR, the clarity in the actual meaning of subjective element of an anti-abuse test should be defined. Otherwise the decisionmaking engine would include a part with flaws, causing built-in bias in its output. 
Figure 3. The qualification of steps in the decision tree model as objective/subjective or as a decision of the decision maker

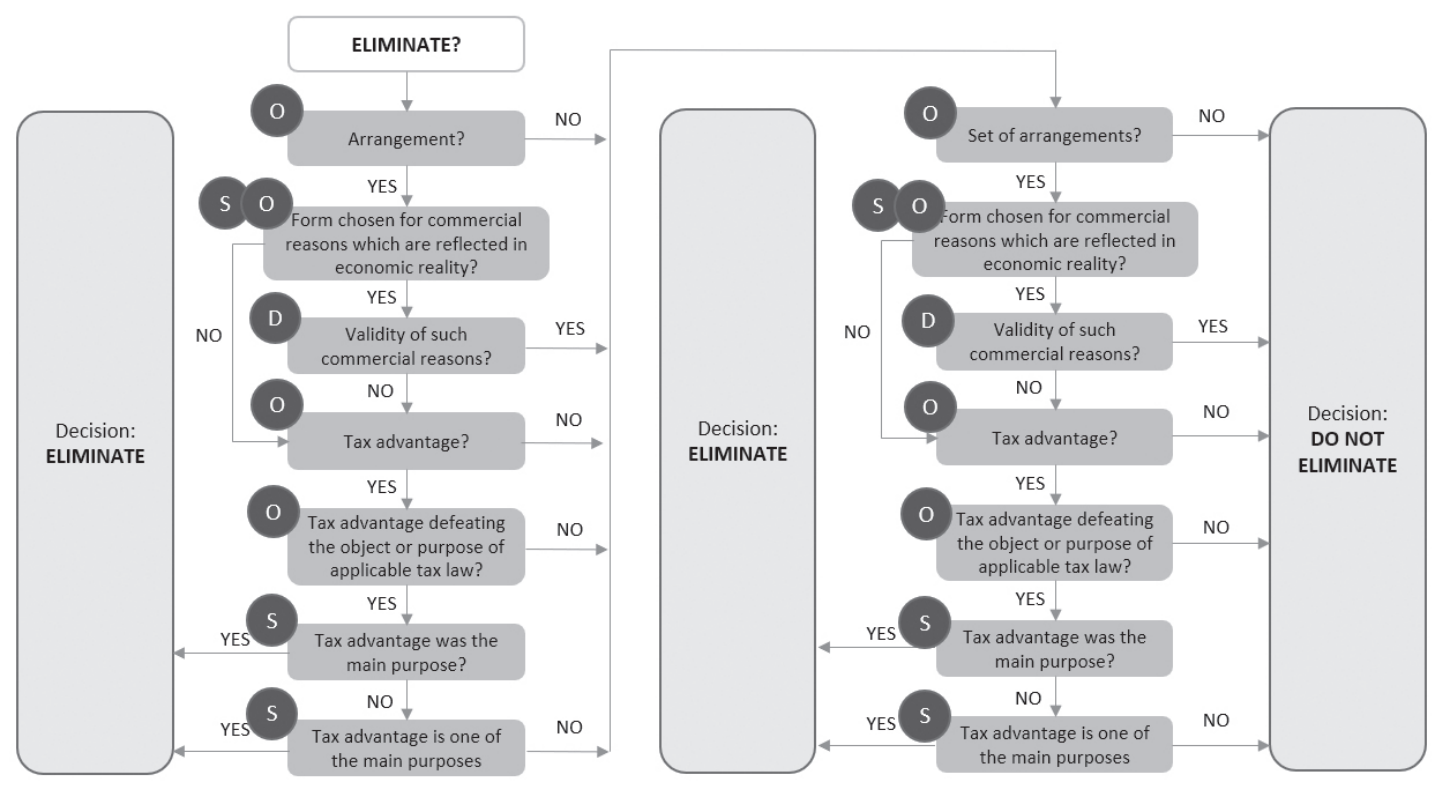

\section{Conclusions}

Automation of the GAAR would have many benefits, starting from spotlighting abusive tax schemes for third parties (such as public notaries), helping taxpayers to understand what is allowed and what is not and demanding more clarity and analysis in legislative processes. The algorithm design would entail decision points which would rely on information either of objective or subjective nature. While development and integration of digital processes and databases would make the objective information sourcing easier over time, the real issue comes from unclear wording of law. Preventing designer bias regression tree model would require developing a clear understanding of how to assess the existence of commercial reasons, the validity of such a reason and a reflection of such reasons in economic life (reality).

Kaido Künnapas is a senior lecturer at TalTech Law School of Tallinn University of Technology, a visiting lecturer of tax law at Tartu University Law School and attorney-at-law at Sorainen Law Firm. Dr. Künnapas obtained his doctoral degree from Tartu University Law School. 


\section{References}

Aarno, A. (1996), Õiguse tõlgendamise teooria [The theory of legal intepretation], Tallinn: Avatud Eesti Fond.

Allahyari, M.; Pouriyeh, S.; Assefi, M; Safaei, S.; Trippe, E. D.; Gutierrez, J. B. \& Kochut, K. (2017), 'A brief survey of text mining: Classification, clustering and extraction techniques,' 23rd ACM SIGKDD Conference on Knowledge Discovery and Data Mining, KDD2017, Halifax Nova Scotia, Canada, August 13-17, 2017. Retrieved from https://arxiv.org/pdf/1707.02919.pdf [accessed 27 Feb 2021]

Council Directive (EU) no. 2016/1164 of 12 July 2016 on laying down rules against tax avoidance practices that directly affect the functioning of the internal market (ATAD), OJ L 193, 19.7.2016, pp. 1-14.

Council Directive (EU) no. 2017/952 of 29 May 2017 amending Directive (EU) 2016/1164 as regards hybrid mismatches with third countries (ATAD II), OJ L 144, 7.6.2017, pp. 1-11.

Frey, C. B. \& Osborne, M. A. (2017), 'The future of employment: how susceptible are jobs to computerization?' Technological Forecasting \& Social Change, vol. 114, pp. 254-280. https://doi.org/10.1016/j.techfore.2016.08.019

Helsgaun, K. (2019), 'Ten project proposals in artificial intelligence.' Retrieved from http://akira.ruc.dk/ keld/teaching/Projektforslag/AI_Projects.pdf [accessed 25 Feb 2021]

Hill, R. K. (2016), 'What an algorithm is,' Philosophy \& Technology, vol. 29, no. 1, pp. 35-59. https://doi.org/10.1007/s13347-014-0184-5

de Jong, S. \& Derksen, S. (2019), 'Binary translation of legislation and case law-A Deep Learning dive into the possibilities of natural language processing for legislation and case law,' Research paper, Tax \& Technology Pt. II, Tilburg University, 14 June.

Jordan, M. I. \& Mitchell, T. M. (2015), 'Machine learning: Trends, perspectives, and prospects' Science, vol. 349, no. 6245, pp. 255-260. https://doi.org/10.1126/ science.aaa 8415

Kõrgessaar v. Tax Board [2001], Administrative Chamber of the Estonian Supreme Court, no. 3-3-1-57-00, 15.1.2001.

Künnapas, K. (2020), 'Dysfunctionality from the sovereignty conflict in the ATAD GAAR,' TalTech Journal of European Studies, vol. 10, no. 1(30), pp. 97-122. https://doi.org/10.1515/bjes-2020-0006

Kuzniacki, B. (2018), 'The artificial intelligence tax treaty assistant: decoding the principal purpose test,' Bulletin for International Taxation, vol. 72, no. 9, pp. 524-534, IFBD Online Journals. 
Kuzniacki, B. (2021), 'Poland's implementation of EU GAAR compromises constitutional and EU principles,' Intertax, vol. 49, no. 3, pp. 237-253.

Longarte, I. (2020), 'Embedding AI and blockchain into next-generation tax policy design,' LawAhead. Retrieved from https://lawahead.ie.edu/embedding-a-iand-block-chain-in-the-next-generation-digitalized-economy-tax-policy-design/ [accessed 10 Jan 2020]

Maret Lilleorg v. Tax Board [2012], Administrative Chamber of the Estonian Supreme Court, no. 3-3-1-79-11, 13.2.2012.

Marge Sirge v. Tax Board [2011], Administrative Chamber of the Estonian Supreme Court, no. 3-3-1-15-11, 25.4.2011.

Mittelstadt, B. D.; Allo, P.; Taddeo, M.; Wachter, S. \& Floridi, L. (2016), 'The ethics of algorithms: Mapping the debate,' Big Data \& Society, vol. 3, no. 2, pp. 1-21. https://doi.org/10.1177/2053951716679679

Narits, R. (2004), Õiguse entsüklopeedia [Encyclopaedia of law], Tallinn: Juura.

OAO Neftyanaya Kompaniya Yukos v. Russia [2011], ECHR 14902/04, 20.10.2011.

OECD (2014), Addressing the Tax Challenges of the Digital Economy, OECD/G29 Base Erosion and Profit Shifting Project, OECD Publishing.

OECD (2019), OECD Model Tax Convention on Income and on Capital: Condensed version 2017, OECD Publishing. http://dx.doi.org/10.1787/mtc_cond-2017-en

Pianatavigna, P. (2018), 'The role of the subjective element in tax abuse and aggressive tax planning,' World Tax Journal, vol. 10, no. 2.

Proposal for a Regulation of the European Parliament and of the Council Laying down harmonised rules on artificial intelligence (Artificial Intelligence Act) and amending certain Union legislative acts, European Commission, 2021/0106 (COD), 21.4.2021.

Raso, F. A.; Hilligoss, H.; Krishnamurthy, V.; Bavitz, C. \& Kim, L. (2018), Artificial Intelligence \& Human Rights: Opportunities \& Risks, The Berkman Klein Center for Internet \& Society Research Publication Series, no. 6. https://doi.org/10.2139/ssrn.3259344

Solarte-Vásquez, M. C. \& Nyman-Metcalf, K. (2017), 'Smart contracting: A multidisciplinary and proactive approach for the EU digital single market,' Baltic Journal of European Studies, vol. 7, no. 2(23), pp. 208-246. https://doi.org/10.1515/bjes-2017-0017

de Wilde, M. F. (2018), 'Is the ATAD's GAAR a Pandora's Box?' in P. Pistone \& D. Weber (eds.) The Implementation of Anti-BEPS Rules in the EU: A Comprehensive Study, Amsterdam: IBFD Online Books, pp. 301-328.

Yale Law School, Information Society Project \& Immuta (2017), Governing Machine Learning. Exploring the Intersection Between Machine Learning, Law, and Regulation. Retrieved from https://law.yale.edu/sites/default/files/area/center/ isp/documents/governing_machine_learning_-_final.pdf [accessed 15 Jan 2020] 
Yan, C. (2019), 'Economic substance: a machine learning perspective on the multi-factorial analysis,' Blue J legal, 22 April. Retrieved from https://www. bluejlegal.com/blog/economic-substance-machine-learning-analysis [accessed 25 Feb 2021]

Zalnieriute, M.; Moses, L. B. \& Williams, G. (2019), 'The rule of law and automation of government decision-making,' The Modern Law Review, vol. 82, no. 3, pp. 425-455. https://doi.org/10.1111/1468-2230.12412

Zimmer, F. (2019), 'In defence of general anti-avoidance rules,' Bulletin of International Taxation, vol. 73, no. 4, IFBD Online Journals. 